\title{
Ovarian Dysgerminoma Associated with Pregnancy: A Case Report from the Sylvanus Olympio University Hospital Center
}

\section{Baguilane Douaguibe ${ }^{1}$, Bingo K. M'Bortche², Tina Ayoko Ketevi1 ${ }^{1}$, Akila Bassowa ${ }^{3}$, Dede Ajavon ${ }^{4}$, T. Dare5, Francis Baramna-Bagou1, Komi A. Migbegna1, Abdoul Samadou Aboubakari4, Koffi Akpadza ${ }^{1}$}

\author{
${ }^{1}$ Department of Gynecology and Obstetrics, Sylvanus Olympio University Hospital Center, Lomé, Togo \\ ${ }^{2}$ Togolese Association of Family Well-Being Planning Center (ATBEF), Lome, Togo \\ ${ }^{3}$ Department of Gynecology and Obstetrics, Campus University Hospital Center, Lomé, Togo \\ ${ }^{4}$ Department of Gynecology and Obstetrics, University Hospital Center, Kara, Togo \\ ${ }^{5}$ Department of Pathology, University Teaching Hospital of Lomé, Lomé, Togo \\ Email: *douaguibe@hotmail.com, mbortche@yahoo.fr, tketevi@yahoo.fr, akilabassowa@gmail.com,ddajavon@yahoo.fr, \\ fbararmnabagou@gmail.com, martize07@gmail.com, anourislam@yahoo.fr, akpadza@yahoo.fr
}

\begin{abstract}
How to cite this paper: Douaguibe, B., M'Bortche, B.K., Ketevi, T.A., Bassowa, A., Ajavon, D., Dare, T., Baramna-Bagou, F., Migbegna, K.A., Aboubakari, A.S. and Akpadza, K. (2021) Ovarian Dysgerminoma Associated with Pregnancy: A Case Report from the Sylvanus Olympio University Hospital Center. Open Journal of Obstetrics and Gynecology, 11, 830-835.

https://doi.org/10.4236/ojog.2021.117077
\end{abstract}

Received: March 19, 2021

Accepted: July 6, 2021

Published: July 9, 202

Copyright $\odot 2021$ by author(s) and Scientific Research Publishing Inc. This work is licensed under the Creative Commons Attribution International License (CC BY 4.0).

http://creativecommons.org/licenses/by/4.0/

\begin{abstract}
Background: Dysgerminoma is a germ cell tumor of the ovary usually found in young women. It represents $1 \%$ to $2 \%$ of all ovarian cancers. The preoperative diagnosis is generally difficult. The surgery and the pathology study are therefore essential for the diagnosis, and optimal management. The incidence of pregnancy with dysgerminoma is extremely low. The treatment and management during pregnancy often jeopardize the materno-fetal prognosis. We report a case of ovarian dysgerminoma in an 18-year-old pregnant woman. Observation: Patient was an 18-year-old, female with no known past medical history, who presented to the emergency room at 29 weeks +3 days pregnancy with dyspnea and a voluminous uterus (height $42 \mathrm{~cm}$ ). An ultrasound showed an active pregnancy, and a large vascularized, finely echogenic, multi-partitioned, thick-walled liquid ovarian tumor. Ca125 was $231.5 \mathrm{IU} / \mathrm{ml}$. Ovarian dysgerminoma was suspected. The surgery and the pathology study of the surgical specimen confirmed the suspected diagnosis. Patient died on postoperative day 8 . Conclusion: Ovarian dysgerminoma is a rare malignant tumor, which must be suspected in case of complex ovarian mass of young women. When diagnosed during pregnancy, its management jeopardizes the materno-foetal prognosis.
\end{abstract}

\section{Keywords}

Dysgerminoma, Young, Pregnancy, Adnexectomy 


\section{Introduction}

Ovarian dysgerminoma is a germ cell tumor of the ovary usually described in young women. It represents $1 \%$ to $2 \%$ of all ovarian neoplasms [1]. This is a rapidly growing tumor, which can present with very variable clinical pictures. The preoperative diagnosis is generally difficult. Eighty-five percent of patients with dysgerminoma have unilateral disease, and most patients are diagnosed with stage Ia of disease [2]. The incidence of pregnancy with dysgerminoma is very low [3]. Surgery and pathology study are therefore essential for the diagnosis and optimal management.

We report a case of ovarian dysgerminoma in an 18-year-old pregnant woman and the difficulty of her management.

\section{Observation}

Patient was an 18-year-old primigravidae at 29 weeks +3 days pregnancy, with no known past medical history who had never done ANC. She was seen at the Emergency Room with dyspnea and voluminous uterus. The physical exam noted a deterioration of the general condition, tachypnea $(30 / \mathrm{min})$, over distended abdomen with collateral venous circulation, $42 \mathrm{~cm}$ of UH, (Figure 1(a)) no signs of labor. An ultrasound showed a progressive pregnancy of 29 weeks, and a large finely echogenic, multi-partitioned, thick-walled liquid tumor. The tumor was abdomino-pelvic located and pushed back the full intra-abdominal organs. The patient was hospitalized for foetal lung maturation, and successive cesarean section, exploration of the abdominal cavity with resection of the tumor.

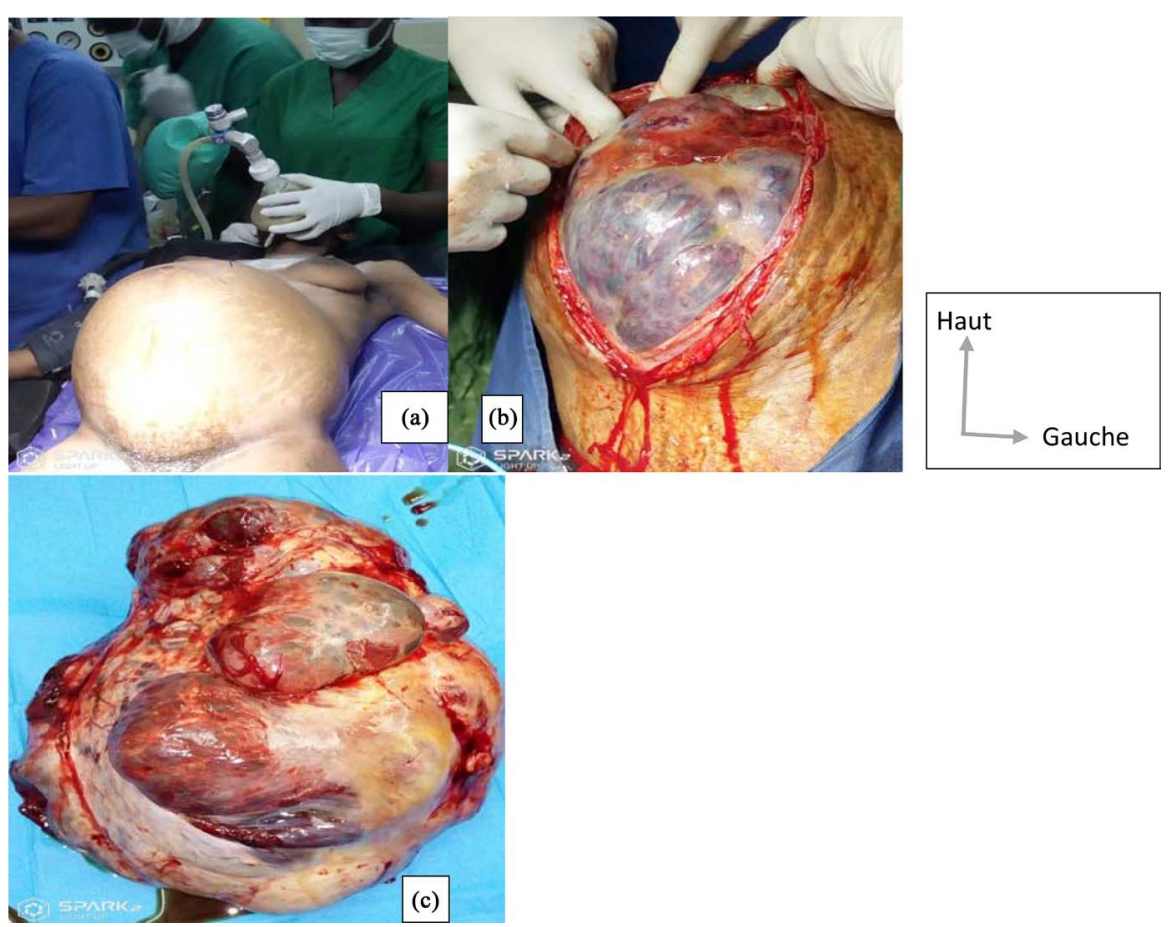

Figure 1. Image of ovarian tumor ((a) an over distended abdomen with collateral venous circulation, (b) tumor after abdomen incision, (c) tumor after ablation: $09 \mathrm{~kg}, 15 \mathrm{~cm}$ ). 
Ca125 was elevated $(231.5 \mathrm{IU} / \mathrm{ml})$. The surgery was scheduled after 48 hours of antenatal corticosteroid therapy, but patient returned in labor the day before the planned surgery and delivered a $2010 \mathrm{~g}$ fresh stillborn.

However, a laparotomy was performed and we observed a rupture of the cystic part of the tumor in the peritoneal cavity. Right adnexectomy was performed (Figure 1(b), Figure 1(c)). Partial omentectomy was performed also. The ovarian tumor weighted 9 kilograms, and measured $15 \mathrm{~cm}$ of length.

The pathology study of the tumor diagnosed a $14 \times 15 \mathrm{~cm}$ right ovarian dysgerminoma, invading the omentum. It was therefore stage II according to the FIGO classification (Figure 2).

The postoperative course was complicated by a progressive deterioration of consciousness. By the $5^{\text {th }}$ postoperative day, a comatose state had developed. On the $7^{\text {th }}$ postoperative day, the onset of a fever of $41^{\circ} \mathrm{C}$, not sensitive to antipyretics, despite the triple antibiotic therapy, quickly led to the death of the patient in 24 hours.

Blood cultures, CRP, lochia cultures and ECBU were all normal. Brain CT scan was not performed due to the limited financial means of the spouse.

\section{Discussion}

The germ cell tumors of the ovary differ from the epithelial-type ovarian tumors. In fact, epithelial tumors of the ovary originate from the surface of the ovary, from the epithelium of coelomic origin, while germ cell tumors originate from primordial germ cells. Germ cells are identified in the region of the allantois and the adjacent part of the yolk sac of a three-week-old (five-week amenorrhea) embryo. The germ cells then immigrate into the embryonic area, to the region where the gonad will form (lumbar region near Wolff's body). Dysgerminoma is a neoplasia of the primordial germ cell that has not yet acquired its potential for differentiation. Due to their different embryological origin, germ cell tumors of the ovary have a totally different epidemiology, prognosis, and therapy from epithelial tumor of the ovary.

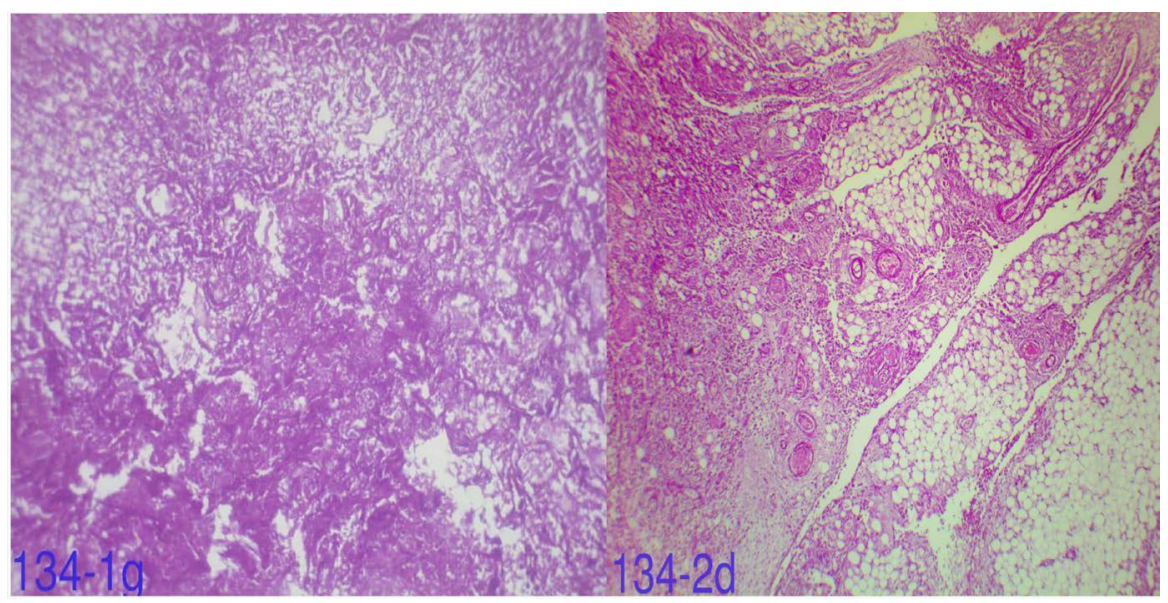

Figure 2. Histology result (dysgerminoma of ovarian). 
Although these tumors represent around $8 \%$ of all ovarian cancers in some studies [4], they are of considerable importance since most cases (75\%) occur in children and young adult. In our case study, patient was an 18 years old woman.

Dysgerminoma associated with pregnancy is extremely rare [3] [5] [6], however, there are sporadic cases in the literature [7]. When the diagnosis is made during pregnancy, a spontaneous delivery at term is rare [6] [8]. In our study, the reported case had expelled a fresh stillbirth at 29 weeks 6 days.

The growth of dysgerminoma is most often rapid. Patients will therefore present with symptoms secondary to an abdominal mass or pain due to ovarian torsion or rupture with hemoperitoneum [1]. Sometimes, this tumor might burly symptomatic and discovered during a routine consultation. The diagnosis is often made in young adults (age less than 30 years) [7] [9], putting their fertility at risk [9]. It is revealed by clinical and paraclinical polymorphism (abdominal distension, abdomino-pelvic mass, persistent menometrorrhagia, pelvic pain, elevation of beta-HCG without notion of pregnancy ...) [1] [10]. In our case the diagnosis of dysgerminoma was suspected based on a large finely echogenic, multi-compartments thick walled, vascularized fluid ovarian tumor on abdominopelvic ultrasound associated with an elevated CA-125 and confirmed by histology (Figure 2).

The treatment of dysgerminomas is surgical [1] [3] [5]. The treatment of dysgerminoma associated with pregnancy is very delicate and considers three factors simultaneously (the fetus, the mother, and the malignant nature of the tumor). Decisions about each case should be individual, considering the patient's age, parity, current pregnancy desire, future fertility, tumor stage and gestational age. Surgery in the first trimester is still controversial because the risk of early abortion is high [7]. In our case a double intervention was recommended (a cesarean section and a tumorectomy).

The patient delivered the day before the planned multidisciplinary team surgery.

The outcome is often favorable with cases of subsequent pregnancy [5]. However, a case of peritoneal carcinoma was revealed after surgery [11], as well as a contralateral involvement [5].

According to some studies, treatment and monitoring are based on the determination of LDH, alpha-fetoprotein, hCG [5].

Regarding tumor markers, alpha-fetoprotein, HCG and LDH (lactate dehydrogenase) are of undeniable utility in the monitoring of non-dysgerminomatous germ cells. But for dysgerminomas, there is not really a marker that can serve as an indicator in their monitoring. Indeed, dysgerminomas do not produce tumor markers, and there is no consensus on the matter. However, cases of dysgerminoma associated with production of chorionogonadotrophic hormone (HCG) have been described. The possibility of a mixed tumor with a choriocarcinomatous component could explain this production of HCG. Indeed, the presence of a choriocarcinoma in association with a dysgerminoma is rare but has already been reported in several 
series [12]. Some authors therefore recommend measuring alpha-fetoprotein, HCG and LDH in dysgerminomas, so as not to omit a mixed component tumor, especially if the tumor has not been completely resected [5] [12]

In our case, the evolution was complicated with death in a context of deterioration of the general condition and fever.

\section{Conclusion}

Dysgerminoma is a rare malignant tumor. It must however be suspected in the presence of a complex ovarian mass in an adolescent and young adult. When the diagnosis is made early, the therapies offer a total cure with the conservation of fertility. When diagnosed during pregnancy, its management jeopardizes the maternofetal prognosis.

\section{Ethics Approval and Consent to Participate}

This study was approved by the "Comité de Bioéthique pour la Recherche en Santé (CBRS)" (Bioethics Committee for Health Research) from the Togo Ministry of Health, Ref N0: 0101/2016/MS/CAB/DGS/DPLET/CBRS.

\section{Availability of Data and Materials}

Extracted data are with the authors and available for sharing on request.

\section{Authors Contributions}

BD was responsible for the conception of the study, participated in the study design, performed the surgery, and wrote the paper. BKM, TAK $\mathrm{AB}, \mathrm{DA}, \mathrm{FB}$, KAM, ASB were involved in the treatment and follow-up of the patient; they have reviewed the paper. KA was responsible for the overall scientific management of the study and the preparation of the final paper. All the authors have read and approved the final paper to be submitted for publication.

\section{Conflicts of Interest}

The authors declare no conflicts of interest regarding the publication of this paper.

\section{References}

[1] Koshy, M., Vijayananthan, A. and Vadiveloo, V. (2005) Malignant Ovarian Mixed Germ Cell Tumour: A Rare Combination. Biomedical Imaging and Intervention Journal, 1, e10.

[2] Kurman, R.J., Carcangiu, M.L., Herrington, C.S. and Young, R.H. (2014) WHO Classification of Tumors of Female Reproductive Organs. International Agency for Research on Cancer, Lyon, 4th Edition.

[3] Yoon, K.L., Chang, Y.Y., Guisera, L. and Dong, C. (2011) Ovarian Dysgerminoma Associated with Pregnancy. Korean Journal of Obstetrics and Gynecology, 54, 218-222. https://doi.org/10.5468/KJOG.2011.54.4.218

[4] Lokossou, A., Akpo-Akélé, M.T., Azon-Kouanou, A., Aguidan, L.A., Houngbé, F. 
and Pérrin, R.X. (2011) Les cancers de l'ovaire en milieu hospitalier à cotonou. Carcinol clin afrique, 10, 29-33.

[5] Yuichiro, S., Tohru, H., Hidetaka, Y., Ichiro, N., Naoya, K., Jasmina, P., et al. (2017) Dysgerminoma and Pregnancy. Serbian Medical Society.

[6] Gauza, E.J., Reberti, A.G., Silva, J.C., Pope, L.Z.B., da Rocha dos Santos, J.C. and Quintana, S.M. (2010) Diagnosis of Ovarian Dysgerminoma during Pregnancy. Revista da Associação Médica Brasileira, 56, 517-519. https://doi.org/10.1590/S0104-42302010000500009

[7] Chen, Y.Y., Luo, Y., Han, C., Tian, W.Y., et al. (2018) Ovarian Dysgerminoma in Pregnancy: A Case Report and Literature Review. Cancer Biology \& Therapy, 19, 649-658. https://doi.org/10.1080/15384047.2018.1450118

[8] Kafil, A., Ahmad, S.S., Kumar, A. and Afshan, N. (2011) Dysgerminoma with Pregnancy and Viable Baby: A Case Report. Oman Medical Journal, 26, 198-200. https://doi.org/10.5001/omj.2011.48

[9] Goyal, L.D., Kaur, B. and Badyal, R.K. (2019) Malignant Mixed Germ Cell Tumors of the Ovary: A Series of Rare Cases. Journal of Reproduction \& Infertility, 20, 231-236.

[10] Schmitt, C., Lamblin, G., Buenerd, A. and Mellier, G. (2010) Elévation de l'HCG en dehors dun contexte gravidique à propos de deux cas. Journal de gynecologie obstétrique et de biologie de reproduction, 39, 675-678. https://doi.org/10.1016/j.jgyn.2010.09.001

[11] Takeshi, I. and Junji, O. (2020) Late Recurrence in Ovarian Dysgerminoma Presenting as a Primary Retroperitoneal Tumor: A Case Report and Review of the Literature. Case Reports in Pathology, 2020, Article ID 4737606. https://doi.org/10.1155/2020/4737606

[12] Talerman, A. (2002) Germ Cell Tumors of the Ovary. In: Kurman, R.J., Ed., Blaustein's Pathology of the Female Genital Tract, Springer-Verlag, New-York, 968-971. 